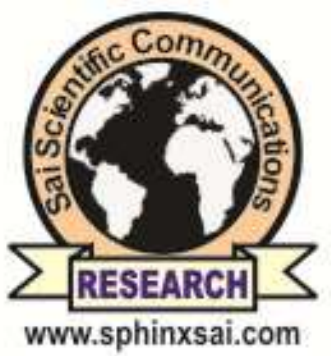

Pharmigatin

International Journal of PharmTech Research

CODEN (USA): IJPRIF, ISSN: 0974-4304, ISSN(Online): 2455-9563

Vol.13, No.02, pp 94-102,

2020

\title{
Effect of Drying Temperatures on Chemical compounds and Antioxidant properties of Vitex negundo kaves
}

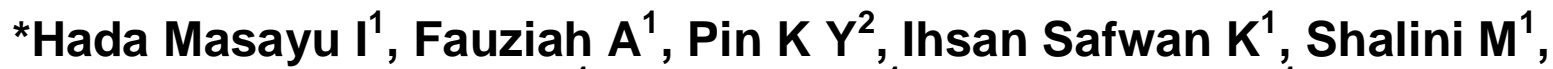 \\ Fadzureena $\mathrm{J}^{1}$,Nor Azah $\mathbf{M}^{1} \mathrm{~A}$ and Sharmizi $\mathrm{I}^{1}$
}

\author{
${ }^{1}$ Natural Products Division, Forest Research Institute Malaysia (FRIM) 52109 Kepong, \\ Selangor, Malaysia \\ ${ }^{2}$ Innovation and Commercialisation Division, Forest Research Institute Malaysia \\ (FRIM) 52109 Kepong, Selangor, Malaysia
}

\begin{abstract}
The effect of drying temperature on the leaves of Vitex negundo was determined. Three levels of temperatures $\left(40,50\right.$ and $\left.60^{\circ} \mathrm{C}\right)$ were used in the presented study. The initial moisture content of the leaves was $69.98 \%$. Continuous drying at the above mentioned temperature levels was conducted to determine the drying time required to achieve equilibrium moisture content. The quality of dried leaves was evaluated based on the quantity of agnuside, a major compound in $V$. negundo using HPLC analysis. The fastest drying of the leaves was achieved at $60^{\circ} \mathrm{C}$, followed by at $50^{\circ} \mathrm{C}$, but HPLC results showed that dried $V$. negundo suffered at $40 \%$ reduction in agnuside content when drying at $60^{\circ} \mathrm{C}$ as compared to at $40^{\circ} \mathrm{C}$. Slight reduction of agnuside was found in the sample dried at $50^{\circ} \mathrm{C}$ as compared to at $40^{\circ} \mathrm{C}$. Whereas, antioxidant results showed that $V$. negundo leaves have significant level of phenolic content and the effect of drying at higher temperature has significantly reduce the amount of phenolics in $V$. negundo leaves. Total phenolic content of $V$. negundo leaves was highest at 50 ${ }^{\circ} \mathrm{C}$ drying temperature. Based on the findings of this work, the best convection oven drying condition for $V$. negundo leaves was at $50^{\circ} \mathrm{C}$ with the highest agnuside concentration of $502.224 \mathrm{mg} / \mathrm{L}$ and phenolic content of $286.7 \pm 11.0 \mathrm{mg} \mathrm{GAE} / 100 \mathrm{~g}$.

Key Words :Vitex negundo, agnuside, drying, phytochemical.
\end{abstract}

\section{Introduction}

The genus Vitex (Verbenaceae) consists of trees and shrubs, found in tropical and subtropical regions. There are about 30 species available in the Malesian region. The most important medicinal species, V. negundo and V. trifolia, are widely cultivated not only for their medicinal properties but also as ornamental and hedge plants, and have sometimes naturalized.The leaf extract of $V$. negundo has been reported to reveal a wide range of biological actions including mosquito repellent activity, anti-angiogenic, hepatoprotective, analgesic,

Hada Masayu I et al /International Journal of PharmTech Research, 2020,13(2): 94-102.

DOI= http://dx.doi.org/10.20902/IJPTR.2019.130212 
antiinflammatory, anti-arthritic, antimicrobial, antihistaminic, central nervous system (CNS)depressant and antifilarial activities. These actions may be due to the various phytoconstituents present in the plant, which include iridoids, flavonoids, polyphenolic compounds, alkaloids, terpenoids etc ${ }^{1}$.Owing to these various phytochemicals, this plant has a crucial role in phytomedicine.

Drying is an important process in material preparation because it reduces the moisture content of fresh herbs for long storage and minimizes the costs of transportation and preservation. However, drying conditions have been shown to have significant influences on the quality and stability of bioactive compounds, and their antioxidant properties. V. negundo shows the presence of numerous iridoids like agnuside, negundoside and its responsible for the different pharmacological activities. Among these iridoids, agnuside is an important chemotaxonomic marker that can be used in quality control of $V$. negundo raw material.

On the other hand, antioxidants are well accepted as dietary supplements as it is proven to improve defense mechanism in human body ${ }^{2}$. During dehydration, antioxidant compounds and its activity often depleted $^{3}$.A study reported before ${ }^{4}$ has suggested that drying is the main mechanism factor to cause the reduction in polyphenol content.Polyphenols are abundant in plants and regards as the main contributor of antioxidant capability of most plants. Many previous studies have found that antioxidant properties of plants were proportional to their phenolicscontent ${ }^{5,6}$. The redox properties of phenolic compounds were attributed by their hydroxyl group, allowing them to act as antioxidant ${ }^{7}$. Among the most common polyphenols found in the plants are caffeic acid, gallic acid and ferrulic acid ${ }^{8}$.

In the present work, the effects of drying temperatures were studied to produce high quality dried material of $V$. negundo leaves. The quality will be evaluated based on agnuside content quantified by high performance liquid chromatography (HPLC) analysis and antioxidant activity from DPPH and total phenolic content.DPPH is a radical which is commonly used for determination of antioxidant properties of plant extracts. It is crucial to perform drying at its optimum condition to prevent any damages to the dried materials. To date, there were no previous studies reported on drying for this $V$. negundo leaves.

\section{Material and Methods}

\section{Raw Material}

Fresh plant of V.negundo was harvested from Maran Research Station, Forest Research Institute Malaysia (FRIM). The plant was sorted manually for its leaves to be used in the experiments. The leaves were cleaned from dirt using tap water, rinsed and then kept in polystyrene box while being transported to the laboratory. Initial moisture content of the leaves was $69.98 \pm 5.42 \%$ (wet basis) measured via calibrated Halogen Moisture Analyser (Model AND MS-70, Japan).

\section{Drying experiments}

The drying experiments were done at three selected temperatures of 40,50 and $60^{\circ} \mathrm{C}$. Lab scale convection oven dryer (UFE 500 type, Memmert, Germany) was used in this study. For the experiments, anapproximate weight of $5.00 \mathrm{~g}$ leaves of Vitex negundo was distributed uniformly on aluminium tray placed in the drying chamber. Sample mass was measured by weighing the tray outside the drying chamber periodically using an electronic balance. Weights were recorded every 10 minutes until the equilibrium moisture content was reached for the calculation of moisture content during experiment. Each drying experiment was triplicated. Final moisture content was determined using Halogen moisture analyser.

The free moisture versus drying time graphs was plotted for each of the experiments. Moisture content (dry basis) of the sample was described by the percentage equivalent of the ratio of the weight of water to the total weight of the dry material. It was calculated by using equation as below?

Moisture content $=(\mathrm{M} / \mathrm{S}) \times 100$

Where $\mathrm{M}$ is the content of water and $\mathrm{S}$ is the content of solid. 


\section{Curves Fitting}

Experimental data obtained were fitted to the three well-known thin layer drying models given in Table 3.5. These models require the calculation of dimensionless moisture ratio, which is given by equation $3.3^{10}$ :

Moisture ratio $=\underline{\mathrm{M}-\mathrm{M}_{\mathrm{e}}}$

$$
\mathrm{M}_{\mathrm{o}}-\mathrm{M}_{\mathrm{e}}
$$

Where $\mathrm{M}, \mathrm{M}_{\mathrm{e}}$ and $\mathrm{M}_{\mathrm{o}}$ are moisture content at any time, equilibrium moisture content and initial moisture content, respectively.

Table 1. Mathematical models applied to the drying curves

\begin{tabular}{|c|l|l|c|}
\hline Model no & Model name & \multicolumn{1}{c|}{ Model } & Reference \\
\hline 1 & Page & $\mathrm{MR}=\exp \left(-\mathrm{kt}^{\mathrm{n}}\right)$ & {$[11]$} \\
\hline 2 & Midili & $\mathrm{MR}=\mathrm{a} \exp \left(-\mathrm{kt}^{\mathrm{n}}\right)+\mathrm{bt}$ & {$[12]$} \\
\hline 3 & Logarithmic & $\mathrm{MR}=\mathrm{a} \exp \left(-\mathrm{kt}^{\mathrm{n}}\right)+\mathrm{b}$ & {$[13]$} \\
\hline
\end{tabular}

The coefficient of determination $\left(\mathrm{R}^{2}\right)$ was the primary criterion for selecting the best model to describe the drying curves ${ }^{14}$. In addition to $\mathrm{R}^{2}$, root mean square error (RMSE) analysis was used to determine the goodness of the fit. The higher the value of $\mathrm{R}^{2}$ and the lowest values of RMSE, the better the goodness of the $\mathrm{fit}^{12}$. They were calculated using equation 3.5 and $3.6^{13}$ :

$$
\begin{gathered}
R^{2}=1-\left[\frac{\sum_{i=1}^{N}\left(M R_{\exp , i}-M R_{\text {pre }, i}\right)^{2}}{\sum_{i=1}^{N}\left(M R_{\exp , i}-\overline{M R_{\exp }}\right)^{2}}\right] \\
R M S E=\left[\frac{1}{N} \sum_{i=1}^{N}\left(M R_{\exp , i}-M R_{\text {pre }, i}\right)^{2}\right]^{1 / 2}
\end{gathered}
$$

Where $\mathrm{MR}_{\text {exp, } \mathrm{i}}$ is the ith experimentally observed moisture ratio, $\mathrm{MR}_{\text {pre, } \mathrm{i}}$ is the ith predicted moisture ratio, $\mathrm{N}$ the number of observations.

\section{Phytochemical Qualitative and Quantitative Analysis}

\section{Instrumentation:}

HPLC chromatograms are generated with Waters HPLC system composing of a quaternary pump (Waters 600E), an autosampler (Waters 717) and a PDA detector (Waters 2996 PDA) scanning from $190 \mathrm{~nm}$ to $400 \mathrm{~nm}$ using a reversed phase C-18 column (4.6 i.d. x $250 \mathrm{~nm}, 5 \mu \mathrm{m})$. TheChromatograph are processed using Empower 2 software.

\section{Sample preparation of $V$. negundo leaves for HPLC analysis:}

The dried and ground sample $(0.5 \mathrm{~g})$ is extracted in $15 \mathrm{ml}$ of HPLC grade methanol by sonication in a closed vial for $15 \mathrm{~min}$. The solution is filtered using $0.45 \mu \mathrm{m}$ filter before subjected to HPLC analysis. An aliquot of $10 \mu \mathrm{L}$ is injected for the analysis.

\section{Preparation of standard solutions for HPLC analysis:}

Stock solutions of agnuside $(1 \mathrm{mg} / \mathrm{mL})$ was prepared separately in methanol. The prepared standard solutions were sonicated and filtered through a $0.45 \mu \mathrm{m}$ membrane filter prior to analysis. 


\section{HPLC analysis:}

The analysis was carried out on a RP-18 column using $0.1 \%$ formic acid (solvent A) and acetonitrile (solvent B) as mobile phase in gradient mode. The gradient elution profile used was: 0 min, $10 \% \mathrm{~B} ; 7 \mathrm{~min}, 30 \%$ B; $15 \mathrm{~min}, 40 \% \mathrm{~B} ; 18 \mathrm{~min}, 100 \% \mathrm{~B}$. The column was equilibrated with $10 \% \mathrm{~B}$ for $5 \mathrm{~min}$ before the next injection. $10 \mu \mathrm{L}$ of standards and sample were injected into the HPLC at a flow rate of $1 \mathrm{~mL} / \mathrm{min}$. The agnuside was analyzed at $285 \mathrm{~nm}$.

\section{Determination of Antioxidant activity of in Dried V. negundo}

\section{DPPH Free Radical Scavenging Activity of in Dried V. negundo:}

Antioxidant reducing activity on DPPH radical is estimated according to the method of Blois (1958) with modification into a high-throughput microplate system. Extracts of dried V. negundo $(50 \mu \mathrm{lof} 1.0 \mathrm{mg} / \mathrm{ml})$

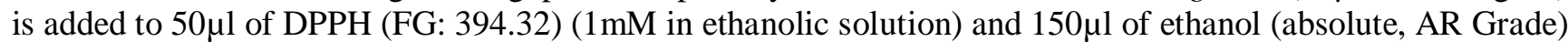
in a 96 well microtiter plate, in triplicates. The plate is shaken $(15 \mathrm{~s}, 500 \mathrm{rpm})$ and left to stand at room temperature for 30 minutes. The absorbance of the resulting solution is measured spetrophotometrically at 520 $\mathrm{nm}$.

\section{Determination of Total Phenolic Content of in Dried V. negundo:}

Determination of TPC on GTE was performed using Folin-Ciocalteu reagent according to the method of Singleton and Rossi, 1965, with modifications into high-throughput microplate system. Distilled water $0.1 \mathrm{ml}$ and $0.1 \mathrm{ml}$ diluted Folin-Ciocalteu reagents $(0.1 \mathrm{ml} / 0.9 \mathrm{ml})$ were added to $50 \mu 1$ of dried $V$. negundo extracts. The sample ( $V$. negundo with Folin-Ciocalteu reagent) were set aside for 5 min before $0.1 \mathrm{ml} 7.5 \%$ sodium carbonate (w/v) was added. After 2 hours, the absorbance was measured at $765 \mathrm{~nm}$ wavelength using a spectrophotometer. The calibration curve of gallic acid (GA) was used for the estimation of sample activity capacity.

\section{Results and Discussion}

\section{Drying characteristics of Vitex negundo leaves}

Figure 1 illustrates the change of free moisture over time for V.negundo leaves dried using convection oven drying.It is clear that the moisture content decreased with increasing time during drying process. It took 500,330 and 140 minutes to dry the leaves at respective temperature of 40,50 and $60^{\circ} \mathrm{C}$. Higher drying temperature resulted in shorter drying times. Drying at 50 and $60^{\circ} \mathrm{C}$ could reduce about 34 and $72 \%$, respectively of drying time as compared to drying at $40^{\circ} \mathrm{C}$. This might be due to larger driving force for heat transfer at temperature 60 and $50^{\circ} \mathrm{C}$ as compared with at temperature $40^{\circ} \mathrm{C}$.

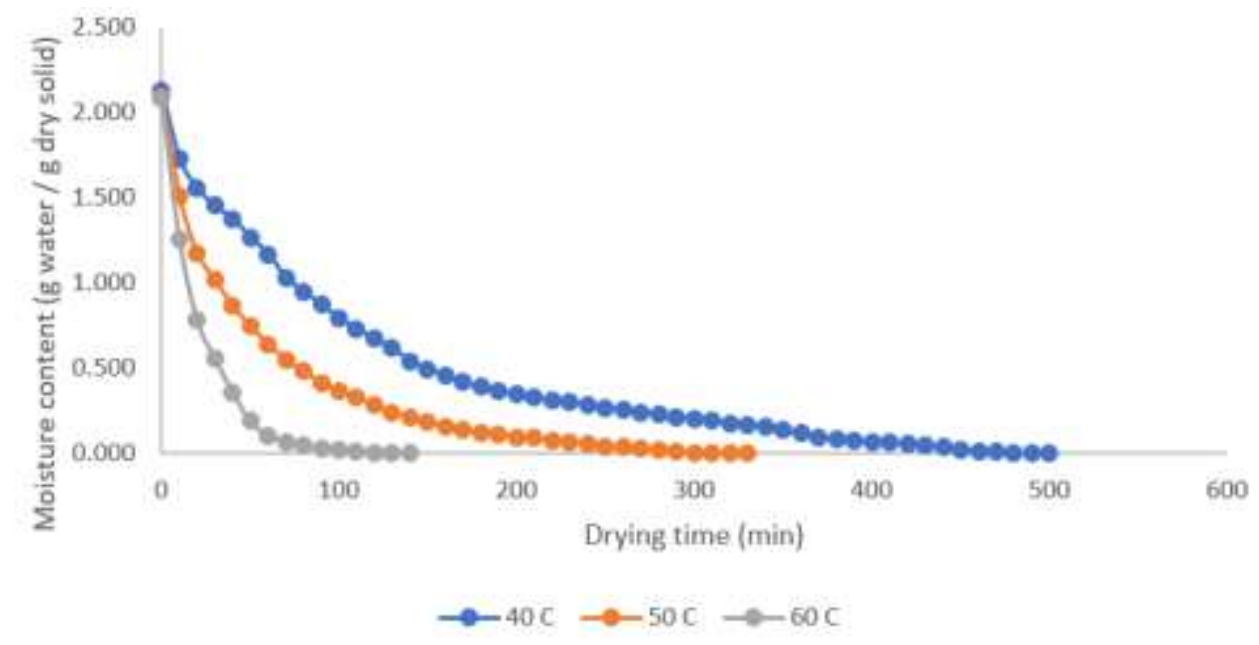

Figure 1. Drying curves of $\mathrm{V}$. negundo leaves dried at 40,50 and $60^{\circ} \mathrm{C}$ using convection oven 
Figure 2 represents drying rate curves of $V$. negundo leaves dried using convection oven at 40, 50 and $60^{\circ} \mathrm{C}$. The entire drying process took place at the falling rate period. The drying rate of the leaves dropped rapidly at the first stage of falling rate period. A slight constant rate period was observed at $40^{\circ} \mathrm{C}$ drying condition. stage, the rate of drying depends greatly on the mechanism by which the moisture from inside the leaves was transferred to the surface. The second falling rate period take much longer than the constant rate period because the drying is slow in order to reach its equilibrium moisture content.

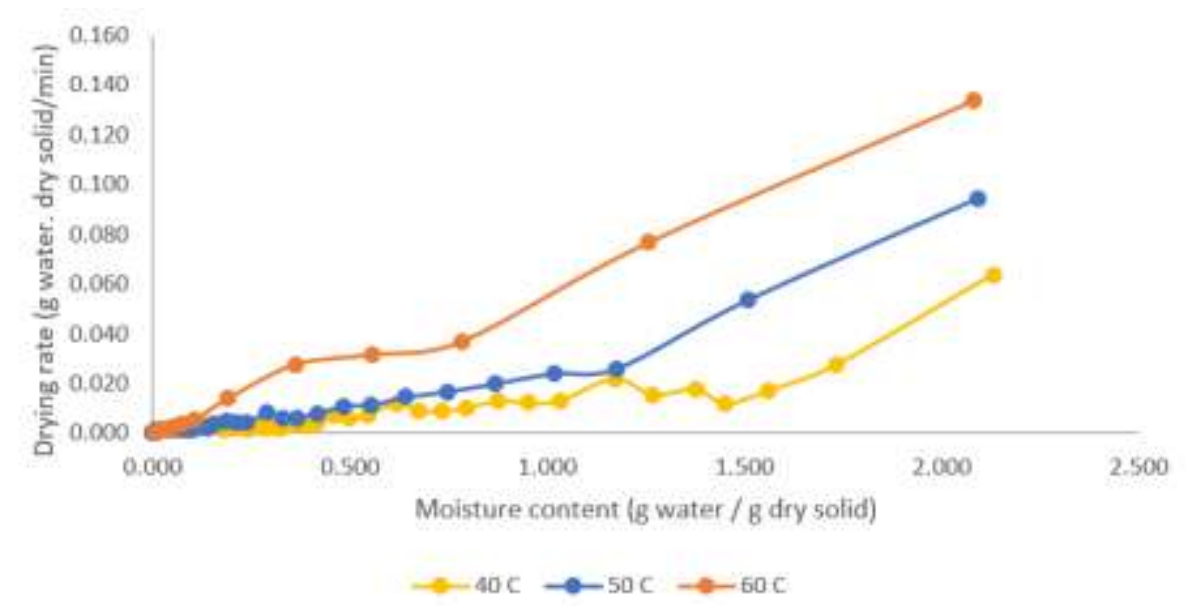

Figure 2.Drying rate curves of $V$. negundo leaves dried at 40,50 and $60^{\circ} \mathrm{C}$

\section{Curve fitting of Drying Process by Convection Oven of $V$. negundo Leaves}

By using SOLVER in Microsoft Excel 2016, the parameters of all the thin-layer models were solved for $\mathrm{R}^{2}$ close to unity with the lowest values of RMSE. The values of the evaluation criteria for all the experiments were given in Table 2. All models showed high $R^{2}\left(R^{2}>0.9\right)$ and low RMSE values (RMSE < 0.05) which proved that selected models can actually described the convection oven drying processof $V$. negundo leaves. Midili model was the most suitable model to fit the drying kinetics of convection oven drying of $V$. negundo leaveswithin studied parameters. This is because its $\mathrm{R}^{2}$ values were closest to unity. The plot of experimental data and the best-fitted model was shown in Figure 3.

Table 2.The values of $\boldsymbol{R}^{2}$, RMSE and drying constants for thin-layer drying models from convection oven drying of V.negundo leaves

\begin{tabular}{|c|c|c|c|c|c|c|c|}
\hline \multirow{2}{*}{$\begin{array}{c}\text { Drying } \\
\text { Temperature } \\
\left({ }^{\circ} \mathrm{C}\right)\end{array}$} & \multirow{2}{*}{$\begin{array}{l}\text { Drying } \\
\text { model }\end{array}$} & \multicolumn{4}{|c|}{ Constant } & \multicolumn{2}{|c|}{ Coefficients } \\
\hline & & $\mathbf{k}$ & b & $\mathbf{a}$ & $\mathbf{n}$ & $R^{2}$ & RMSE \\
\hline 40 & \multirow{3}{*}{ Midili } & 0.02372 & -0.00005 & 0.98480 & 0.80310 & 0.99915 & 0.01343 \\
\hline 50 & & 0.06385 & -0.00007 & 0.99863 & 0.71293 & 0.99989 & 0.00427 \\
\hline 60 & & 0.05804 & -0.00006 & 0.99752 & 0.93977 & 0.99966 & 0.00738 \\
\hline 40 & \multirow{3}{*}{ Page } & 0.02151 & & & 0.83326 & 0.99884 & 0.01569 \\
\hline 50 & & 0.05581 & & & 0.75181 & 0.99953 & 0.00887 \\
\hline 60 & & 0.05599 & & & 0.95405 & 0.99957 & 0.00830 \\
\hline 40 & \multirow{3}{*}{ Logarithmic } & 0.00908 & 0.01438 & 0.90627 & & 0.99825 & 0.01931 \\
\hline 50 & & 0.01899 & 0.02015 & 0.89142 & & 0.99603 & 0.02571 \\
\hline 60 & & 0.04736 & -0.00174 & 0.99104 & & 0.99946 & 0.00935 \\
\hline
\end{tabular}




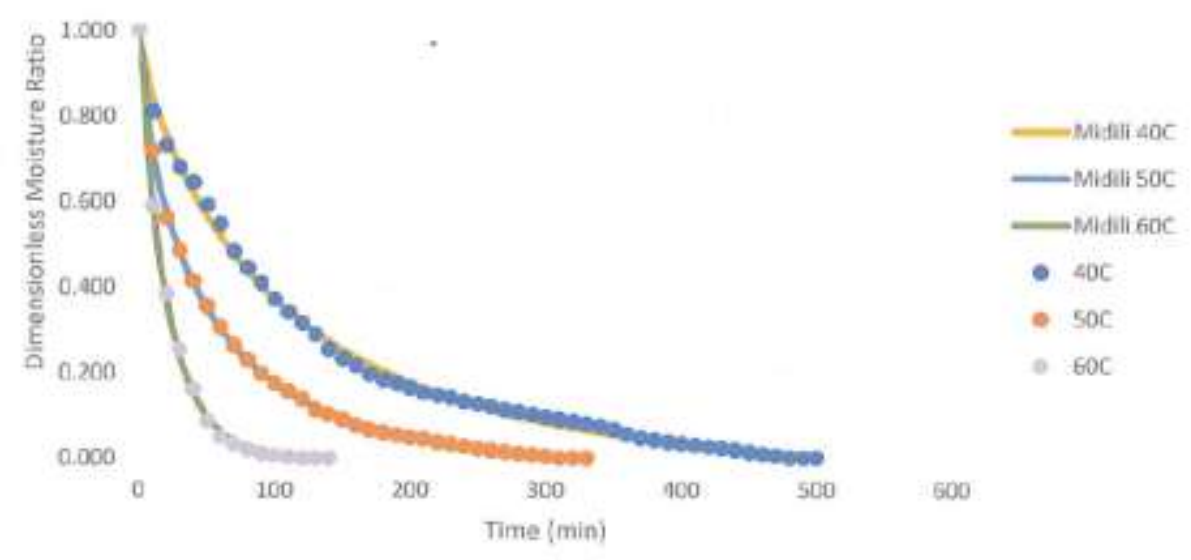

Figure 3. Comparison between the experimental data and the best fitted model for drying of $V$. negundo leaves at 40,50 and $60^{\circ} \mathrm{C}$

\section{Phytochemical content of $V$. negundo leaves from convection oven drying}

Concentration of agnuside in convection oven dried leaves of $V$. negundo and HPLC chromatograms are illustrated in Figure 4 and 5 respectively. The figure shows that the concentration of agnuside was decreasing with increasing temperatures. Vitex negundo leaves dried at 40,50 and $60^{\circ} \mathrm{C}$ contained agnuside concentration of $535.377 \mathrm{mg} / \mathrm{L}, 502.224 \mathrm{mg} / \mathrm{L}$ and $320.574 \mathrm{mg} / \mathrm{L}$, respectively. The slight reduction of agnuside was observed when the leaves were dried at $50^{\circ} \mathrm{C}$ as compared to at $40^{\circ} \mathrm{C}$. The drop of concentration of agnuside was significant in the leaves dried at $60^{\circ} \mathrm{C}$ when compared to at 40 and $50^{\circ} \mathrm{C}$ indicates that it might be due to the destruction of agnuside during drying as a result of thermal damage.

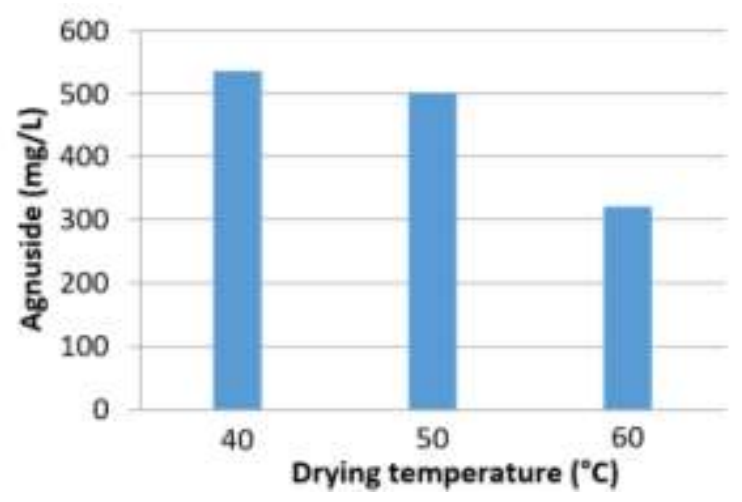

Figure 4. Concentration of $V$. negundo in dried leaves subjected to different drying temperatures 

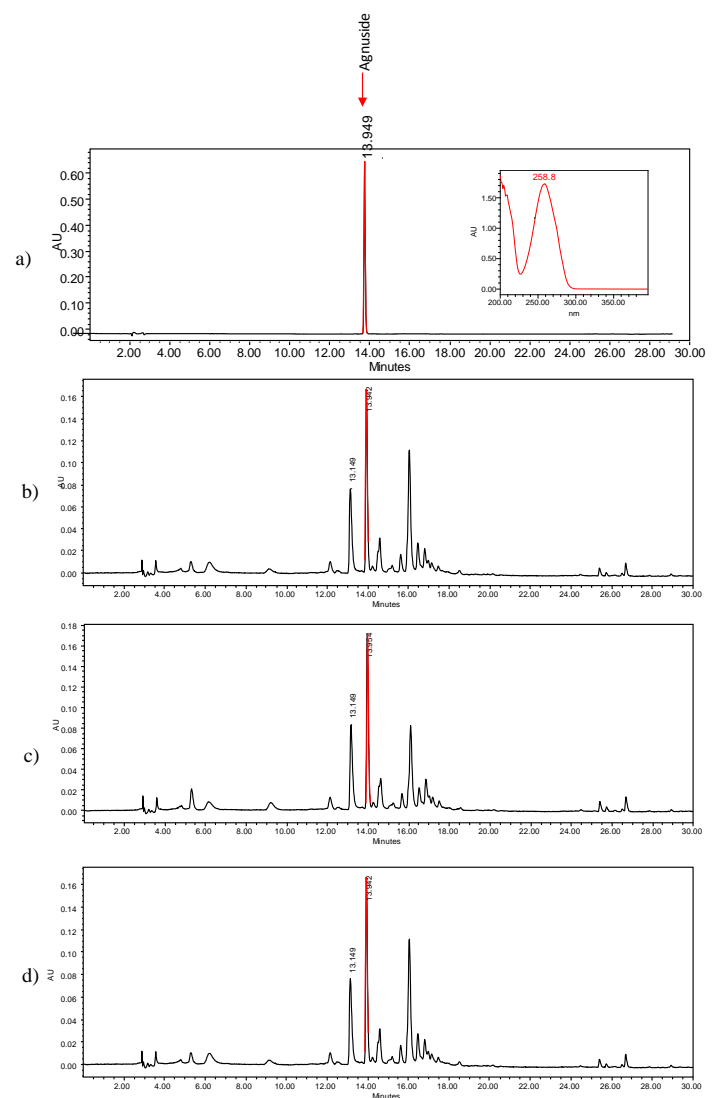

Figure 5. HPLC chromatograms of (a) standard; (b) leaves dried at $40^{\circ} \mathrm{C}$; (c) leaves dried at $50^{\circ} \mathrm{C}$; (d) leaves dried at $60^{\circ} \mathrm{C}$

\section{Antioxidant Activities of $V$. negundo leaves}

In this study, total phenolic content of dried leaves of $V$. negundo were observed by analysing their gallic acid equivalent (GAE). The result showed that $V$. negundoleaves have significant level of phenolic content and the effect of drying at higher temperature has significantly reduce the amount of phenolics in $V$. negundo leaves. Total phenolics content of $V$. negundo leaves dried at $40,50,60$ and $70^{\circ} \mathrm{C}$ were $270.8 \pm 34.7$, $286.7 \pm 11.0,250.8 \pm 11.2$ and $231.2 \pm 10.9 \mathrm{mg} \mathrm{GAE} / 100 \mathrm{~g}$ of samples, respectively (Table 1). Green tea, which was used as positive control exhibited highest total phenolics content with $920.2 \pm 71.2 \mathrm{mg}$ GAE/100g of sample. These results indicated that total phenolic content of $V$. negundo leaves was highest at $50{ }^{\circ} \mathrm{C}$ drying temperature and it was inversely proportional to the drying temperature after $50{ }^{\circ} \mathrm{C}$.

In the present study, DPPH radical scavenging activity of $V$. negundo leaves dried at different temperatures was also determined. The results indicated that the DPPH scavenging effects of $V$. negundo leaves dried at $40,50,60$ and $70{ }^{\circ} \mathrm{C}$ were $81.53 \pm 2.64,81.46 \pm 2.79,74.35 \pm 2.63$ and $78.06 \pm 2.43 \%$, respectively (Table 1). These data suggest that the DPPH radical scavenging of $V$. negundo leaves dried at different temperature did not significantly altered except for $60^{\circ} \mathrm{C}$ drying temperature.

High drying temperature was found to give negative effect on antioxidant properties of $V$. negundo leaves as well as their phenolics content. These results were in agreement with previous study performed by previous study ${ }^{15}$ which indicated that antioxidant capacity of plants were significantly affected by high drying temperature ${ }^{15}$. Similar finding ${ }^{16}$ was found which dictate that phenolic acids are susceptible to destruction at increased temperatures. Study on the effect of different drying temperature $\left(40,50,70 \& 100{ }^{\circ} \mathrm{C}\right)$ of $\mathrm{V}$. negundo leaves on their antioxidant properties has also been performed before ${ }^{17}$ and their findings also produced similar results which indicated that drying temperatures of 70 and $100{ }^{\circ} \mathrm{C}$ have significantly reduced their phenolics content and antioxidant properties. 
Table 3. Total phenolic content and DPPH scavenging activity of methanol extract of $\mathrm{V}$. negundo leaves dried at $40{ }^{\circ} \mathrm{C}, 50{ }^{\circ} \mathrm{C}, 60{ }^{\circ} \mathrm{C}$ and $70{ }^{\circ} \mathrm{C}$. Values with different letter are significantly different $(p<0.05)$.

\begin{tabular}{|c|c|c|}
\hline $\begin{array}{c}\text { Methanol extracts of } \boldsymbol{V} . \\
\text { negundo leaves dried at } \\
\text { different temperatures } \\
\left({ }^{\circ} \mathbf{C}\right)\end{array}$ & $\begin{array}{c}\text { Phenolic content } \\
(\mathbf{m g} \text { GAE/100 g samples) }\end{array}$ & DPPH Scavenging (\%) \\
\hline 40 & $270.8 \pm 34.7^{\mathrm{a}, \mathrm{b}}$ & $81.53 \pm 2.64^{\mathrm{a}}$ \\
\hline 50 & $286.7 \pm 11.0^{\mathrm{a}}$ & $81.46 \pm 2.79^{\mathrm{a}}$ \\
\hline 60 & $250.8 \pm 11.2^{\mathrm{a}, \mathrm{b}}$ & $74.35 \pm 2.63^{\mathrm{b}, \mathrm{c}}$ \\
\hline 70 & $231.2 \pm 10.9^{\mathrm{b}}$ & $78.06 \pm 2.43^{\mathrm{a}, \mathrm{b}}$ \\
\hline
\end{tabular}

\section{Conclusion}

In term of quality with regards to drying time and phytochemical content, the best convection oven drying condition forV.negundo leaves was at $50^{\circ} \mathrm{C}$ with $502.224 \mathrm{mg} / \mathrm{L}$ of agnuside concentration and $286.7 \mathrm{mg}$ $\mathrm{GAE} / 100 \mathrm{~g}$ samples of phenolic content.

\section{References}

1. Patil S. P. andLaddha K.S. Extraction efficiency of agnuside from Vitex negundo leaves using different techniques and its quantitative determination by HPLC. International Journal of Health Science and Research, 2018, 8:129-135.

2. Fu, L., Xu, B.T., Gan, R.Y., Zhang,Y., Xu, X.R., Xia, E.Q. and Li, H.B. Total phenolic contents and antioxidant capacities of herbal and tea infusions. International Journal of Molecular Sciences, 2011, 12: $2112-2124$.

3. Manzocco, L., Anese, M. and Nicoli, M.C. Antioxidant properties of tea extracts as affected by processing. LWT-Food Science and Technology, 1998, 31: 694-698.

4. Moure, A., Cruz, J.M., Franco, D., Domínguez, J.M., Sineiro, J., Domínguez, H., Núñez, M.J. and Parajó, J.C. Natural antioxidants from residual sources. Food chemistry, 2001,72: 145-171.

5. 5.Ismail, M., Owisa, A.I., Hettab, M. and Mohammeda, R. Total phenolics and flavonoids content, antioxidant activity and GC/MS analyses of Euphorbia grandialata. Journal of Applied Pharmaceutical Science, 2017,7: 176-181.

6. Da Silva M. N., Koslowsky M. R., Farias W. M., Funchal C. and Dani C.Total Phenolic Content and Antioxidant Activity of Different Types of Chocolate, Milk, Semisweet, Dark, and Soy, in Cerebral Cortex, Hippocampus, and Cerebellum of Wistar Rats. Biochemistry Research International, 2015, 9 pages.

7. Baba, S.A. and Malik, S.A. Determination of total phenolic and flavonoid content, antimicrobial and antioxidant activity of a root extract of Arisaema jacquemontii Blume. Journal of Taibah University for Science, 2015, 9: 449-454.

8. Pandey, K.B. and Rizvi, S.I. Plant polyphenols as dietary antioxidants in human health and disease. Oxidative Medicine and Cellular Longevity, 2009, 2: 270-278.

9. Ramaswamy H. and Marcotte M. Food processing: Principles and applications. CRC press, 2006.

10. (Sacilik et al., 2006): Sacilik, K. (2007). Effect of drying methods on thin-layer drying characteristics of hull-less seed pumpkin (Cucurbita pepo L.). Journal of Food Engineering, 79(1), 23-30.

11. Sobukola et al., 2007Sobukola O. P. \&Dairo O. U. (2007). Modeling drying kinetics of fever leaves (Ocimumviride) in a convective hot air dryer.Nigerian Food Journal 25(1): 146 - 154.

12. Midili et al., 2002 Midilli, A., Kucuk, H., Yapar, Z., (2007). A new model for single-layer drying. Drying Technology: An International Journal, 37-41.

13. Pin et al., 2009 Pin, K. Y., Chuah, T. G., Rashih, a. A., Law, C. L., Rasadah, M. a., \& Choong, T. S. Y. (2009). Drying of Betel Leaves ( Piper betle L.): Quality and Drying Kinetics. Drying Technology, 27(1), 149-155.

14. Guarte, R.C. 1996. Modeling the drying behaviour of copra and development of a natural convection dryer for production of high quality cogra in the Philippines. PhD dissertation. Stuttgart, Germany: Hohenhaim University. 
15. Katsube, T., Tsurunaga, Y., Sugiyama, M., T., Furuno and Yamasaki, Y. Effect of air-drying temperature on antioxidant capacity and stability of polyphenolic compounds in mulberry (Morus alba L.) leaves. Food Chemistry,2009, 113: 964-969.

16. Sun, Y., Shen, Y., Liu, D. and Ye, X. Effects of Drying Methods on Phytochemical Compounds and Antioxidant Activity of Physiologically Dropped Un-Matured Citrus Fruits. LWT-Food Science and Technology, 2015, 60: 1269-1275.

17. Chong, K.L. and Lim, Y.Y. Effects of Drying on the antioxidant properties of herbal tea from selected Vitex species. Journal of Food Quality, 2012, 35: 51-59. 